\title{
SHADOW STATION
}

\section{All the time in the Universe.}

BY CAROLINE M. YOACHIM

$\mathrm{M}$ Mot poole cane

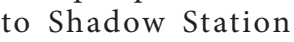
because they're dying.

I'm just here to rescue my sister.

The station used to be near Neptune, but Shadow Station doesn't move. It can't, not while people are in stasis. There can be no movement while time is stopped. So Neptune continues on its orbit, and the Solar System rotates around the centre of the Milky Way. Our Galaxy is moving, too, a million miles per hour. Finding Shadow Station in the vastness of space - light years from Earth - was no easy task, but I did it.

I dock my shuttle. There are hundreds of other shuttles docked to the station's hull, abandoned when their owners entered stasis.

"Welcome to Shadow Station." A caretaker unit meets me inside the airlock. "Stasis is depicted in fiction as people in futuristic-looking pods, resting peacefully. Have a problem with no solution, or a disease with no cure? Go into stasis and wait for a happy ending."

I smile. Jendri must have liked this speech. She's one of those people who reads the first chapter of a book, then immediately skips to the end. She can't relax and enjoy the story unless she knows what happens.

"The reality is far darker than the fiction, both literally and figuratively."

As I follow the caretaker around the station, I search for signs of disrepair. Everything is in excellent condition, but even a well-designed station with carefully programmed caretakers would not last long enough for what I have in mind. I trace the wires embedded beneath my skin, the implant that I've spent the past 40 years developing.

"Freezing people in time turns them into shadows," the caretaker continues, "and no known technology can bring them back. Because if time stops, even light can't escape, and there's no way to change anything." I'm surprised by the caretaker's honesty, but

\section{DNATURE.COM}

Follow Futures:

๖ @NatureFutures

$f$ go.nature.com/mtoodm since TimeStop Medical disincorporated, I guess there's no reason to recruit new patients.
"Yes. The prevailing belief is that reversing stasis is impossible."

People used to believe that faster-thanlight travel was impossible, but here I am, light years from Earth. The caretaker leads me into a vast chamber with row upon row of dark figures - shadows. The domed ceiling is transparent, and an arm of the Milky Way dominates the sky overhead.

I scan the shadows. "Newest patients in front?"

"Yes," the caretaker says. "This one arrived a few decades ago."

The shadows are black holes in human form, so uniformly dark that it is impossible to discern the details of their features, but the silhouette in front of me matches my memory of Jendri.

"If you enter stasis, your place will be here." The caretaker points to the spot next to my sister.

I walk around the periphery of the chamber. There are thousands of people here, most of them standing, staring straight ahead, arms at their sides. A few are facing each other, or turned backwards, or sprawled out across the floor. "The earliest patients to arrive are in the back?"

The caretaker nods. I call up a 3D image of the first patient, Lindsey Morales-Chang. According to my records, she went into stasis because she had cancer. Cancer. Far more easily cured than the stasis, but deadly in her era.

I run an analysis comparing the historical image to the figure standing before me.

She's moved. Not much. Definitely not enough to see with the naked eye, but if time is passing for her, even if it moves glacially slow, the stasis can be reversed. The shadow-patients won't have time to come up with the solution on their own - it took me 40 years with a top-notch team of researchers at Titan University to develop the device embedded beneath my skin. At the speed the shadows move, the Universe would end before they could complete their research. But if I was to take my equipment into stasis, we'd have enough time to use it.

I upload several decades of medical advances to the station's medical facility, cures for all the shadow-patients. The stasis generator is designed to alter time for a person, but I reprogram the field to include the entire station, and all the ships docked outside otherwise our life support would deteriorate long before I could bring everyone out of stasis. I write letters to my friends and family, and sign a contract with the caretaker, freeing a corporation that no longer exists from any threat of legal action. Then all that's left to do is enter stasis and activate my device. There's no way to run a test.

I stand facing my sister.

I tell myself it isn't really stasis, only slowness.

The Universe around me speeds into a blur. Stars swirl across the sky faster than fireflies. I'm 40 years older than Jendri remembers, but in the blink of an eye - two revolutions of the Galaxy - she recognizes me.

"If we hurry, we can all get out of stasis."

"We could. Or you could free the others while we escape in your shuttle. It'll take us an eternity to get anywhere, but it'd be a grand adventure." She grins and takes my hand. "Come with me. I want to know what happens in the end."

Caroline M. Yoachim has written dozens of short stories, many of which are in her new collection, Seven Wonders of a Once and Future World \& Other Stories. Website: carolineyoachim.com 